\title{
The variability of radiative balance elements and air temperature over the Asian region of Russia
}

\author{
E. V. Kharyutkina, I. I. Ippolitov, and S. V. Loginov \\ Institute of Monitoring of Climatic and Ecological Systems, SB RAS, 10/3, Academichesky ave., 634055 Tomsk, Russia \\ Correspondence to: S. V. Loginov (ceo@imces.ru)
}

Received: 17 March 2011 - Published in Biogeosciences Discuss.: 4 May 2011

Revised: 6 January 2012 - Accepted: 4 March 2012 - Published: 27 March 2012

\begin{abstract}
The variability of spatial-temporal distribution of temperature and heat balance elements is investigated for the Asian territory of Russia $\left(45-80^{\circ} \mathrm{N}, 60-180^{\circ} \mathrm{E}\right)$ using JRA-25, NCEP/DOE AMIP-II reanalysis data and observational data for the period of global warming 1979-2008. It is shown that temperature trend over the territory is $1.4^{\circ} \mathrm{C}$ for the period under study according to reanalysis data. Since the beginning of 90 s of 20th century the increase of back earth-atmosphere shortwave radiation is observed. Such tendency is in conformity with the cloud cover distribution and downward shortwave radiation at the surface. Regression model describing temperature variability with variability of heat balance elements was presented. We conclude that possible applications for the model include the convenient estimate of temperature variability according to reanalysis data.
\end{abstract}

\section{Introduction}

One of the main feature of the warming observed since $70 \mathrm{~s}$, according to IPCC 2007, is significant spatial inhomogeneity of temperature change processes. The understanding of the reasons demands the investigation of regional climates and different factors, which influence the climate. Heat balance elements at the surface, determining heat and water exchange between surface and atmosphere, have the important role for air temperature distribution.

Thus, any identified patterns of radiation can be subsequently used to explore potential relationships between surface energy budget and atmospheric circulation or other atmospheric parameters. In addition, identifying regions with common radiation variability and trends may be valuable in understanding of predominant physical processes.
The purpose of this study is to investigate the spatial and temporal variability of air surface temperature and heat balance elements at the surface in the period of global warming 1979-2008 and detection of relationship between temperature and radiative and heat fluxes. This investigation was performed for the Asian territory of Russia (ATR), large climatic region in the north-east Asia.

Radiative balance elements of the atmosphere, as well as sensible and latent heat fluxes between atmosphere and underlying surface play an important role in the weather and climate formation. Significant contribution to the study of these characteristics, which are the part of the earth's surface heat balance, was made by Budyko (1958). Heat transfer for different types of landscapes was studied by Pavlov (1980). Current constructions of radiative balance are based on the analysis of assimilated data, satellite estimates of global radiant and/or the hybrid approach of in-situ and satellite measurements (Da Silva et al., 1994; Trenberth and Solomon, 1994; Rossow and Zhang, 1995; Trenberth and Stepaniak, 2004). The irradiative aspects have been explored in several studies by Zhang et al. (2004, 2006, 2007), based on International Satellite Cloud Climatology Project (ISCCP) cloud data and other data in an advanced irradiative code. In addition, estimates of surface radiation budgets have been given by Gupta et al. (1999) and used by Smith et al. (2002) and Wilber et al. (2006). These are based on earlier ISCCP data and reanalysis databases such as NCEP/NCAR, NCEP AMIP/DOE-II, ERA-40, and JRA-25. Information on radiation fluxes and latent and sensible heat fluxes at the grid nodes covering the entire globe is contained among the output parameters of the reanalysis, and the length of the time series allows to investigate not only the interannual, but also decadal variability. 
There is spatial inhomogeneity of shortwave radiation trend at the surface (Long et al., 2009; Riihimaki et al., 2009; Norris and Wild, 2009; Chiacchio and Wild, 2010). The authors mentioned above obtained subintervals in the temporal dynamics of net radiation at the surface and they connected this variability with aerosol content in the atmosphere. Results of the investigation in long-term variability of incoming solar radiation, cloudiness and air temperature at the surface for the territory of former Soviet Union were presented by Abakumova (1996) for the period of increased aerosol filling of the atmosphere. According to the results of Plakhina at al. (2007, 2009), reduction of atmospheric aerosol over ATR has been observed since 1995 and trend of aerosol optical depth was negative (from -1.0 to $-1.5 \% \mathrm{yr}^{-1}$ ). Such tendency was caused by decadal "purification" of atmosphere from aerosol. It is connected with absence of major volcanic eruptions and anthropogenic ,calm“. Therefore we can suppose that the main factor which influences radiation variability is cloudiness change. Increase of total cloud fraction over ATR was observed from 2001 to 2010 (Khlebnikova et al., 2009; Chernokulsky et al., 2010).

However, studies dedicated to heat and radiative fluxes investigation over ATR, especially during last decades, do not provide complete information for the territory, only for local regions (Zotino, Yakutsk) and these studies are connected with solution of specific problems (Meroni et al., 2002; Tchebakova et al., 2002), for the regions of the North and wetlands (Meroni et al., 2002; Iwahana et al., 2005; Boike et al., 2008).

\section{Data and methods of analysis}

Multivariate statistical techniques were used to understand the spatial and temporal variability of surface temperature and its relation to elements of heat balance. The monthly averaged data of temperature and solar radiation were calculated from NCEP AMIP/DOE-II and JRA-25 reanalysis data. Observational data from 454 stations were used for temperature validation over ATR and northern parts of Kazakhstan, Mongolia and China (Distribution data center NOAA, ftp: //ftp.cdc.noaa). Inclusion of stations of Kazakhstan, Mongolia and China was necessary for correct presentation of meteorological fields over the southern boundary of ATR. Satellite data and observational data from actinometrical stations were used for validation of solar radiation.

JRA-25 data were used as the initial data (the long-term reanalysis cooperative research project carried out by the Japan Meteorological Agency (JMA) and the Central Research Institute of Electric Power Industry CRIEPI, http://jra.kishou. go.jp/JRA-25/index_en.html). The data are presented in the nodes of a regular latitude-longitude grid of $1.25^{\circ} \times 1.25^{\circ}$ at 23 isobaric levels from 1000 to $0.4 \mathrm{hPa}$ with $6 \mathrm{~h}$ temporal resolution. To derive estimates, which characterize the spatial distribution of some quantity $x$ over the territory, its correction on the latitudinal dependence (because of northward mesh decrease) was made: calculated values were multiplied by coefficient, which is equal to contemporary areas ratio. Then, distribution function $\mathrm{F}_{x}(x)$ was constructed for the resulting sample. Sample size was $\sim 2100$ nodes. Median and interquartile scale sample was estimated by the empirical distribution function. Then to assess the correlation we used time series of average sample values, which were determined in the following way.

To estimate the significance of correlation coefficient, the Fisher transformation was used with further one-sided $t$-test of the null hypothesis at 0.05 significance level (von Storch et al., 2003). Standard deviations were determined for coefficients of linear regression equations. In figures with linear regression equations these errors are shown in round brackets. Significance of the slope coefficients in linear regression equations was estimated using the one-sided $t$-test at 0.1 significance level.

To derive multilinear regression equations, a stepwise regression algorithm was applied in Sect. 5. This is a systematic method for adding and removing terms from a multilinear regression model based on the statistical significance of their contribution into the model variability. At each step, the $p$ value (0.05) of an $F$-statistic is computed to test models with and without a potential term (von Storch et al., 2003). If a term is not currently in the model, the null hypothesis is that the term would have a zero coefficient if added to the model. If there is sufficient evidence to reject the null hypothesis, the term is added to the model. Conversely, if a term is currently in the model, the null hypothesis is that the term has a zero coefficient. If there is insufficient evidence to reject the null hypothesis, the term is removed from the model. In multilinear regression equation the number of terms could be comparable with the length of the time series.

\section{Temperature field variability over Asian territory of Russia}

According to IV IPCC Report (2007), linear trend of air surface global temperature for the period of 1906-2005 is $0.074{ }^{\circ} \mathrm{C} / \mathrm{dec}$ ade, this value has significantly increased during last several decades. Global temperature trend value by Assesment report on climate change and its consequences in Russian Federation (2008) was $0.18^{\circ} \mathrm{C} / \mathrm{dec}$ ade, and for temperature, averaged by the territory of Russia, trend value was $0.43^{\circ} \mathrm{C} /$ decade. Spatial and temporal variability of temperature field for period 1976-2005 over Asian territory of Russia is investigated by Ippolitov et al. (2008). Average temperature $\bar{T}$ and trend values $\overline{T_{\text {tr }}}$, obtained in this study and averaged by the territory for every calendar month and for a year in general are presented in Table 1.

From the Table 1 it follows, that for the period of 19762005 the Asian territory of Russia was warmed by more than $1{ }^{\circ} \mathrm{C}$. High positive statistically significant temperature 
Table 1. Annual averaged temperature values and trends, calculated for the period of 1979-2008 over ATR for observational and reanalysis data. Statistically significant values are in bold.

\begin{tabular}{lcccc}
\hline \multirow{2}{*}{ Month } & \multicolumn{2}{c}{ Stations $(1976-2005)$} & \multicolumn{2}{c}{ JRA-25 $(1979-2008)$} \\
\cline { 2 - 5 } & $\bar{T},{ }^{\circ} \mathrm{C}$ & $\overline{T_{\text {tr }}},{ }^{\circ} \mathrm{C} /$ decade & $\bar{T},{ }^{\circ} \mathrm{C}$ & $\overline{T_{\text {tr }}},{ }^{\circ} \mathrm{C} /$ decade \\
\hline Jan & -27.9 & 0.27 & -21.6 & $\mathbf{0 . 9 1}$ \\
Feb & -24.7 & 0.51 & -18.8 & 0.4 \\
Mar & -15.9 & $\mathbf{0 . 6 5}$ & -12.2 & $\mathbf{0 . 9 8}$ \\
Apr & -5.2 & 0.23 & -3.5 & $\mathbf{0 . 5 5}$ \\
May & 4.5 & $\mathbf{0 . 5 5}$ & 6.0 & $\mathbf{0 . 6 3}$ \\
Jun & 13.0 & $\mathbf{0 . 3 7}$ & 14.9 & $\mathbf{0 . 5 2}$ \\
Jul & 16.3 & $\mathbf{0 . 4 6}$ & 18.0 & $\mathbf{0 . 3 4}$ \\
Aug & 13.0 & $\mathbf{0 . 2 6}$ & 14.2 & 0.28 \\
Sep & 5.4 & 0.19 & 6.8 & 0.14 \\
Oct & -5.5 & $\mathbf{0 . 5 7}$ & -3.2 & $\mathbf{0 . 4 8}$ \\
Nov & -18.5 & 0.29 & -13.9 & $\mathbf{0 . 6 5}$ \\
Dec & -26.3 & -0.03 & -19.6 & -0.09 \\
Year & -6.4 & $\mathbf{0 . 3 4}$ & -2.7 & $\mathbf{0 . 4 8}$ \\
\hline
\end{tabular}

trends are revealed in March, May, June, July, August and October.

Over Asian territory of Russia temperature field variability is also characterized by significant spatial inhomogeneity. In January there are differently directed processes over ATR (Fig. 1a). The process of warming is revealed over the central part of Siberia and along seaside, the process of cooling is over West Siberia and Chukotka, and warming is observed over $60 \%$ of the territory. Probability density function of trend values, calculated by grid nodes $1^{\circ} \times 1^{\circ}$, is multimode and has a wide range of trend values from $-1.5^{\circ} \mathrm{C} / \mathrm{dec}$ ade to $+1.5^{\circ} \mathrm{C} /$ decade. Trend value, averaged by the territory, is $0.27^{\circ} \mathrm{C} /$ decade with standard deviation $\sigma_{\mathrm{tr}}=0.84^{\circ} \mathrm{C} / \mathrm{dec}$ ade and it is not statistically significant.

In July (Fig. 1b) the warming is observed over $90 \%$ of the territory, local centers of negative trends are revealed only in West Siberia. Probability trend distribution has one mode with average value $0.46^{\circ} \mathrm{C} /$ decade and standard deviation $\sigma_{\mathrm{tr}}=0.29 \%$ decade. In general, in annual variability over the central part of Siberia the process of warming prevails, and over West Siberia the processes of warming alternate with the processes of cooling. From the comparison of contemporary values according to observational data and JRA-25 (Table 1) it follows, that average temperatures and their trends are higher in reanalysis data however reanalysis data save a qualitatively correct representation of temperature field variability. Correlation coefficient of annual averaged time series for 1979-2005 was 0.95. To maintain unified data format for all derived values, and subsequently for making a regression model we will use temperature field characteristics, calculated by JRA-25 reanalysis data.

\section{Radiation and heat balance fluxes at the earth's surface. The variability of cloud cover}

Validation of downward shortwave radiation, based on network observations of actinometrical stations in West Siberia was carried out in the following method. The monthly sums of solar radiation from NCEP/DOE AMIP-II reanalysis were analyzed, its intra-annual variability and also correlation analysis was carried out for ten actinometrical stations, located in West Siberia and Altai. It was shown that NCEP/DOE AMIP-II reanalysis data represents seasonal variability of monthly sums of solar radiation with error $15 \%$, also over mountain regions. For mountain region basins in the south of Siberia total radiation from reanalysis data was slightly different than that from data of actinometrical stations (no more than $4 \%$ ). Annual average values of total radiation, determined by reanalysis data were higher than values, determined by observational data. For flatland regions of West Siberia annual average values of total radiation, determined by reanalysis data, were overestimated by $12-15 \%$. So, trends were not changed. The validation of JRA-25 reanalysis data and actinometrical stations data has the same results with the validation according to NCEP/DOE AMIP-II reanalysis data: representation of intra-annual variability, systematical overestimation of total downward radiation values by models and the constancy of trend sign, interannual variability.

Validation of JRA data and other reanalyses of the total cloud cover were made in paper by Chernokulsky et al. (2010). It is shown that according to observational data global annual averaged cloudiness value for the Northern Hemisphere is 0.55 , the similar value $(0.44)$ is obtained using JRA reanalysis data and the maximal coincidence with 
a)

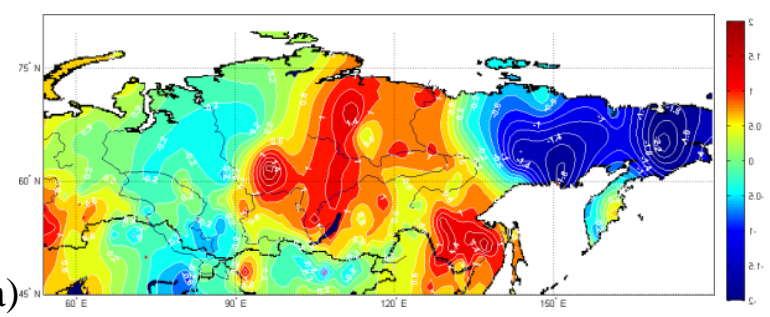

b)

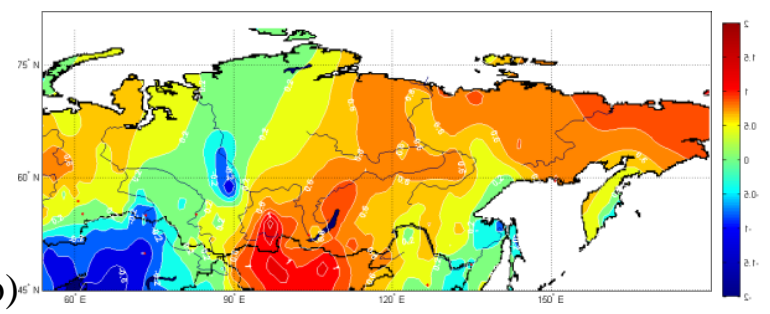

c)

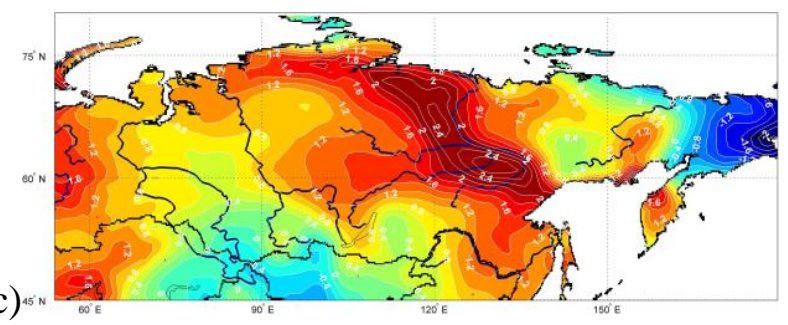

d)

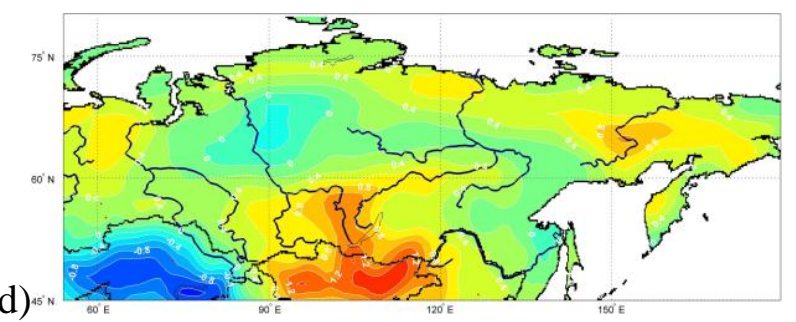

Fig. 1. The spatial distribution of temperature trend values $\left({ }^{\circ} \mathrm{C} /\right.$ decade) over ATR for January and July using observational data (a and $\left.\mathbf{b}\right)$ and JRA-25 reanalysis data (c and $\mathbf{d})$.

observational data is observed for ERA-40. Annual variations of cloud cover, constructed by JRA reanalysis, are also characterized by low values.

We compared the total cloudiness values using NCEP/DOE AMIP (http://www.esrl.noaa.gov/psd/data/ gridded/data.ncep.reanalysis $2 . \mathrm{html}$ ) and JRA-25 for ATR. The comparison showed that the time series related to the interval 1979-2008 are close to each other, the magnitude of discrepancy between time series of monthly averaged values is $1.5 \%$ and the difference of annual averaged values is $0.5 \%$. For the following calculations both reanalysis were used.

Heat balance equation at the surface is:

$B=Q_{\mathrm{n}}+L_{\mathrm{n}}-L E-P-G$,

where $Q_{\mathrm{n}}=Q_{\downarrow \mathrm{s}}-Q_{\uparrow \varsigma}$ - net shotwave radiation; $L_{\mathrm{n}}=L_{\downarrow \mathrm{s}}-$ $L_{\uparrow \mathrm{s}}-$ net longwave radiation, and $L_{\mathrm{n}}=-E_{\text {eff }}$, где $E_{\text {eff }}-$ effective radiation. $L E, P$ and $G$ - latent, sensible fluxes and heat flux in the ground respectively. $Q_{\mathrm{s}}$ and $L_{\mathrm{S}}$ - shotwave and longwave radiation, coming to the surface $(\downarrow)$ or going from the surface $(\uparrow)$.

Symbols in front of $L E, P$ and $G$ depend on heat flux direction. Positive turbulent fluxes are directed away from the earth surface whilst positive net radiation is directed towards the earth surface.

Equation (1) suggests that $B=0$, but for bounded territory we should take into consideration other heat sources, for instance, heat advection with dominant for this region air flows, heat losses by snow-ice cover melting and others. These factors lead to disbalance of $B$. Values of $B$, averaged by the territory were calculated in nodes by (1) using JRA-25 reanalysis (Table 2). These values are small in comparison with heat balance elements (in average $1 \mathrm{~W} \mathrm{~m}^{-2}$, maximal
Table 2. Variability of annual averaged values of $B\left(\mathrm{~W} \mathrm{~m}^{-2}\right)$ over ATR using JRA reanalysis data for 1979-2008.

\begin{tabular}{lrlrl}
\hline Month & $\bar{B}$ & $\sigma_{B}$ & $\overline{B_{\text {tr }}}$ & $\sigma_{B \text { tr }}$ \\
\hline Jan & 1.15 & 1.09 & -0.03 & 0.06 \\
Feb & 0.55 & 1.12 & -0.01 & 0.06 \\
Mar & -0.39 & 1.76 & 0.02 & 0.07 \\
Apr & 1.05 & 3.22 & -0.02 & 0.10 \\
May & 4.83 & 1.18 & 0.17 & 0.20 \\
Jun & 3.35 & 1.18 & -0.01 & 0.16 \\
Jul & 1.56 & 0.75 & -0.02 & 0.04 \\
Aug & 0.98 & 0.72 & -0.02 & 0.04 \\
Sep & 0.07 & 0.94 & -0.01 & 0.04 \\
Oct & -0.27 & 1.38 & 0.00 & 0.06 \\
Nov & -0.45 & 1.06 & -0.03 & 0.06 \\
Dec & 0.55 & 1.18 & -0.00 & 0.06 \\
\hline
\end{tabular}

values $5 \mathrm{~W} \mathrm{~m}^{-2}$ in May), that is why for ATR we do not take them into consideration. On the other hand, if we include horizontal advection in radiative balance calculation in single points (for example, observational stations), then the averaging of values by the territory leads to relative compensation of local fluxes. That is why advection influence could be observed due to global circulation flows, dominant for the territory under study and connected with west transfer. Global circulation variability can describe up to $50 \%$ of air temperature variability in several months, such as April and October (Ippolitov et al., 2010). But in this study only heat balance elements influence on temprerature is investigated. 
a)

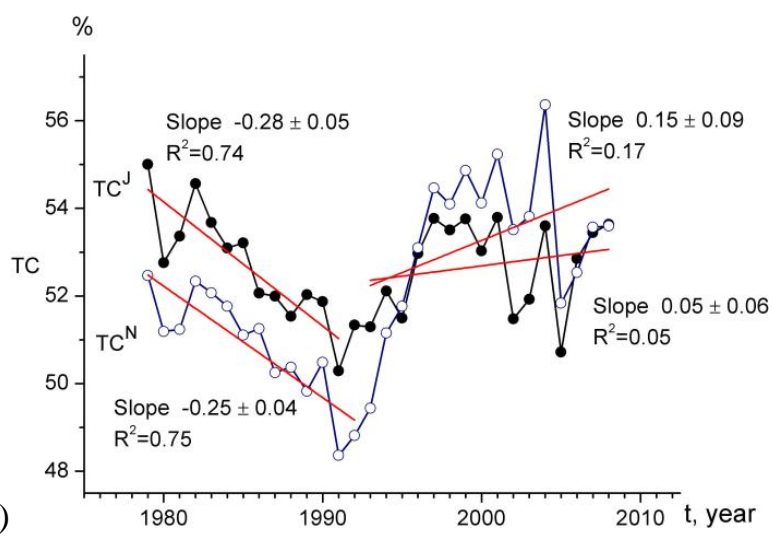

b)

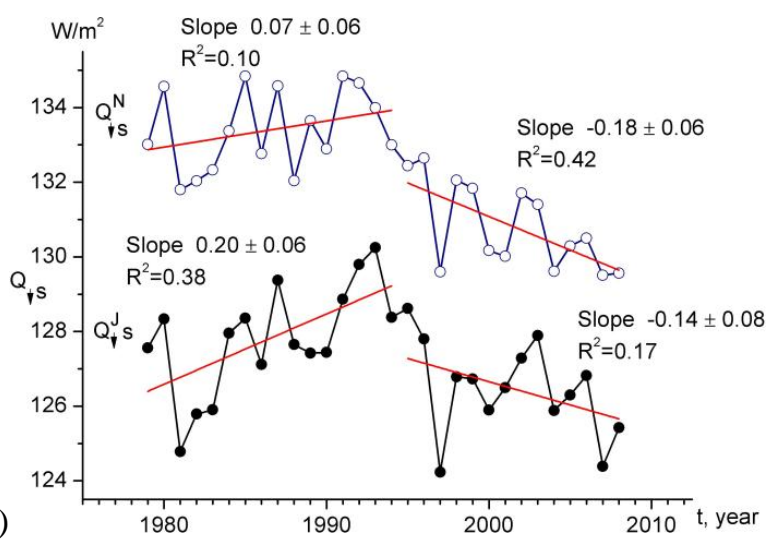

Fig. 2. The temporal variability of total cloud cover (TC) (a) and downward shortwave radiation at the surface $Q_{\downarrow \mathrm{s}}$ (b) over ATR using JRA-25 reanalysis for the period 1979-2008. Symbols "J" and "N" in superscript indicate values. Calculated by JRA-25 and NCEP/DOE AMIP-II respectively.

Shortwave solar radiation coming to the surface plays an important role in radiative balance formation. When solar constant doesn't change, shortwave radiation variability at the surface is caused by cloudiness variability and aerosol content in the atmosphere.

Cloudiness plays an important role in the energy balance of the Earth (Zhang et al., 1995). Clouds contribute to the heating of the earth's surface due to the reradiated infrared radiation toward the earth's surface. On the other hand, clouds efficiently reflect downward solar radiation and contribute to cooling of the climate system. At the present time it is considered that cloud cover slightly cools the climate, while high level clouds contribute to the increasing of greenhouse effect and low clouds - to cooling of the climate system (Chernokulsky et al., 2010).

Interannual variability of total cloudiness $(T C)$ and downward shortwave radiation at the surface $\left(Q_{\downarrow}\right)$ is presented for two reanalysis (Fig. 2).
From the analysis of $T C$ and $Q_{\downarrow s}$ variability over ATR (Fig. 2) it follows that for JRA-25 and NCEP/DOE AMIP reanalysis datasets in subinterval 1979-1992 the decreasing of total cloudiness and the corresponding growth of downward shortwave radiation at the surface are observed. In the second subinterval 1992-2008 the situation is reverse. As it was mentioned above, these periods are probably connected with aerosol contents variability and cloudiness.

Estimates of total cloudiness changes over ATR by observational data at meteorological stations are made by Khlebnikova et al. (2009). It was found there that for the second half of 20th century the total cloudiness trend over ATR is positive and equal to $0.4 \% /$ decade, but for the interval 1976 to 2005 trend is negative and equal to $-0.5 \% /$ decade. There is a certain agreement between these data and JRA reanalysis, shown in Fig. 2, because in general linear trend for the period of 1979-2008 is also negative and equal to $-0.2 \% /$ decade. The results of our analysis of changes in the cloudiness structure have shown that, in general, for the period under study over ATR the following tendency was observed: high level clouds increased by $1 \%$, middle level clouds decreased by $1 \%$, and most markedly decrease by $2 \%$ was observed for the part of low level clouds.

Such temporal variability separation of downward shortwave solar radiation $Q_{\downarrow \text { s }}$ is also observed for interannual variability of zonally averaged values $Q_{\downarrow}$ over ATR and Northern Hemisphere, especially from $50^{\circ}$ to $60^{\circ} \mathrm{N}$ (Fig. 3a). Similar tendency is observed for zone from $60^{\circ}$ to $70^{\circ} \mathrm{N}$ (not presented). Observational data at actinometrical stations in Siberia are in a good agreement with reanalysis data: majority of stations are also characterized by two subintervals in $Q_{\downarrow \text { s }}$ variability (Fig. $3 \mathrm{~b}$ ).

Tendency of downward shortwave solar radiation decrease was also revealed by satellite data for the period of 1983-2005 (http://eosweb.larc.nasa.gov/cgi-bin/sse/sse.cgi? $+\mathrm{s} 01\{\#\} \mathrm{s} 01$ ).

Table 3 shows the monthly averaged values of $T C$ and $Q_{\downarrow}$ over ATR with their standard deviation. The annual averaged longterm cloud cover is $53 \%$. The maximum value is $61 \%$ in November and the minimum is $45 \%$ in July. The maximum variability of cloud cover corresponds to the cold season.

The annual averaged value of shortwave downward solar radiation at the surface was $128 \mathrm{~W} \mathrm{~m}^{-2}$ with maximum value of $269.5 \mathrm{~W} \mathrm{~m}^{-2}$ in July and minimum value of $7 \mathrm{~W} \mathrm{~m}^{-2}$ in December. The maximum of short-wave flux variability was also in cool season of year.

There are also two subintervals in temporal variability of $E_{\text {eff }}$ (according to two reanalysis datasets) with opposite tendencies of long-term changes (Fig. 4). It is shown that since 1995 longwave radiation from the atmosphere $L_{\downarrow s}$ has increased. It is connected with the growth of total cloudiness. Overall cloud impact on radiative balance will depend on spatial distribution and cloud characteristics.

The decreasing of $Q_{\downarrow}$ is observed in the central and northern part of ATR, while the increasing - in the southern part 
Table 3. Variability of monthly averaged values of $T C, Q_{\downarrow S}, L E$ and $P$ over ATR calculated by JRA-25 reanalysis for period 1979-2008. Statistically significant values are in bold.

\begin{tabular}{|c|c|c|c|c|c|c|c|c|}
\hline \multirow[t]{2}{*}{ Month } & \multicolumn{2}{|c|}{$\begin{array}{l}\text { Downward Solar } \\
\text { Radiation }\end{array}$} & \multicolumn{2}{|c|}{$\begin{array}{c}\text { Total } \\
\text { Cloudiness }\end{array}$} & \multicolumn{2}{|c|}{$\begin{array}{c}\text { Latent Energy } \\
\text { LE }\end{array}$} & \multicolumn{2}{|c|}{$\begin{array}{c}\text { Sensible Energy } \\
\text { P }\end{array}$} \\
\hline & $\begin{array}{l}\overline{Q_{\downarrow \mathrm{s}}}, \\
\mathrm{W} \mathrm{m}^{-2}\end{array}$ & $\begin{array}{r}\overline{Q_{\downarrow \mathrm{str}}}, \\
\mathrm{W} \mathrm{m}^{-2 / \text { decade }}\end{array}$ & $\begin{array}{l}\overline{T C}, \\
\%\end{array}$ & $\begin{array}{r}\overline{T C_{\mathrm{tr}}}, \\
\% / \text { decade }\end{array}$ & $\begin{array}{l}\overline{L E}, \\
\mathrm{~W} \mathrm{~m}^{-2}\end{array}$ & $\begin{array}{r}\overline{L E_{\mathrm{tr}}}, \\
\mathrm{W} \mathrm{m}^{-2 / \text { decade }}\end{array}$ & $\begin{array}{r}\bar{P} \\
\mathrm{~W} \mathrm{~m}^{-2}\end{array}$ & $\begin{array}{r}\overline{P_{\text {tr }}}, \\
\mathrm{W} \mathrm{m}^{-2 / \text { decade }}\end{array}$ \\
\hline Jan & 13.7 & -0.04 & 58 & -1.75 & 0.1 & -0.12 & -23.0 & -0.62 \\
\hline Feb & 48.4 & -0.02 & 56 & -0.14 & 1.0 & 0.06 & -17.5 & -0.42 \\
\hline Mar & 116.6 & -1.24 & 53 & 0.44 & 4.6 & 0.48 & -6.8 & -1.22 \\
\hline Apr & 198.9 & -0.70 & 49 & -0.68 & 16.8 & 0.23 & 17.7 & -0.59 \\
\hline May & 252.9 & -1.85 & 48 & -0.62 & 40.0 & 0.47 & 39.3 & -2.56 \\
\hline Jun & 269.5 & -1.79 & 46 & 0.28 & 58.1 & 0.36 & 46.4 & -1.87 \\
\hline Jul & 248.2 & 0.38 & 45 & -0.34 & 62.9 & 0.71 & 39.9 & -0.70 \\
\hline Aug & 186.1 & -1.02 & 50 & 0.44 & 45.1 & -0.03 & 25.3 & -0.39 \\
\hline Sep & 115.5 & -1.00 & 55 & 0.38 & 25.9 & 0.25 & 7.8 & -0.69 \\
\hline Oct & 57.8 & -0.48 & 60 & 0.51 & 10.4 & -0.14 & -11.4 & -0.88 \\
\hline Nov & 20.4 & -0.18 & 62 & -0.73 & 2.3 & -0.1 & -21.0 & -0.03 \\
\hline Dec & 7.0 & -0.03 & 59 & -1.24 & 0.4 & -0.1 & -23.8 & 0.13 \\
\hline
\end{tabular}

of the territory. Also $L_{\downarrow s}$ and $T C$ have the similar spatial distribution and the opposite behavior is observed with $Q_{\downarrow s}$. Spatial distributions of downward shortwave radiation at the surface $Q_{\downarrow}$ and effective radiation $E_{\text {eff }}$ also have anticorrelation with cloudiness variability (Fig. 5).

It is more evident in July over West Siberia, Buryatia and Yakutia. In January $Q_{\downarrow \mathrm{s}}$ variability is not significant, and effective radiation variation is mainly connected with cloudiness variability. There are some regions, which have both correlation and anticorrelation with cloudiness, for instance, Chukotka. Probably, it is connected with advection of moist air from the Pacific Ocean.

Heat exchange between surface and atmosphere takes place through longwave radiation fluxes, and sensible and latent heat fluxes. In temporal dynamics of the effective radiation $E_{\text {eff }}$ two periods with the change of gradient in the beginning of $90 \mathrm{~s}$ are distinguished. In the first interval the effective radiation increased with the rate of $1.96 \mathrm{~W} \mathrm{~m}^{-2} /$ decade, while in the second one it decreased with the rate of $-0.13 \mathrm{~W} \mathrm{~m}^{-2} /$ decade.

In winter mainly zonal distribution is observed with the largest values in the south of the territory. Several local minima occurred along the north part of Pacific coast and over the northern part of West Siberia. The positive trend of the effective radiation is in general typical for the summer period and it is observed in the southern part of East Siberia. This coincides with the region of the total clouds decreasing.

For surface air sensible and latent heat fluxes can be calculated as (Budyko, 1958):

$P=\rho c_{p} D\left(T_{\mathrm{s}}-T\right), \quad L E=\rho D\left(q_{\mathrm{s}}-q\right)$,

here $\rho$ is air density, $c_{p}$ is air heat capacity at a constant pressure, $D$ is the integral characteristic of the vertical turbulent transfer conditions between surface and atmosphere, $T_{\mathrm{s}}$ is surface temperature, $T$ is surface temperature at $2 \mathrm{~m}, q_{\mathrm{s}}, q$ are air specific humidity at temperatures $T_{\mathrm{s}}$. and $T$ respectively. The expression, proposed by Budyko, allows representing latent and sensible heat fluxes in convenient way for the analysis of their variability. These fluxes are determined by the difference between meteoparameters at two levels. Therefore, the investigation of value variability at each level allows explaining the flux variability.

The interval 1990-1996 is also marked out in the temporal dynamics of fluxes. It is characterized by decrease of anomalies amplitude. The wavelet spectrum analysis of monthly averaged time series of $L E$ and $P$ have shown that changes occur in the periodicities with scale less than five years. The monthly averaged values of $L E$ and $P$ over the ATR region with their standard deviation are shown in Table 3.

The latent heat $L E$ trend, in general, is positive, and only $20 \%$ of the territory is in the negative value area. The variability of $L E$ is weak in the winter months, from April, the latent heat flux is increased over the south of West and East Siberia, as well as over Far East. From June negative trend is observed over the south of West Siberia, positive - over the central and southern part of East Siberia and Far East. In general the conformity of $L E$ spatial distribution with cloud field is marked. We could not explain this negative trend by difference between trends of specific humidity $q_{s}$ and $q$ at the appropriate height.

Negative tendency prevails in the change of sensible heat flux $P$. This is due to a lower rate of temperature growth $T_{\mathrm{s}}$, than $T$ at height of $2 \mathrm{~m}$. This conclusion is based on the comparison of temperature linear trends at appropriate vertical levels. Opposite tendencies of longterm variability of $L E$ and $P$ are in a good agreement with Ban-Weiss 

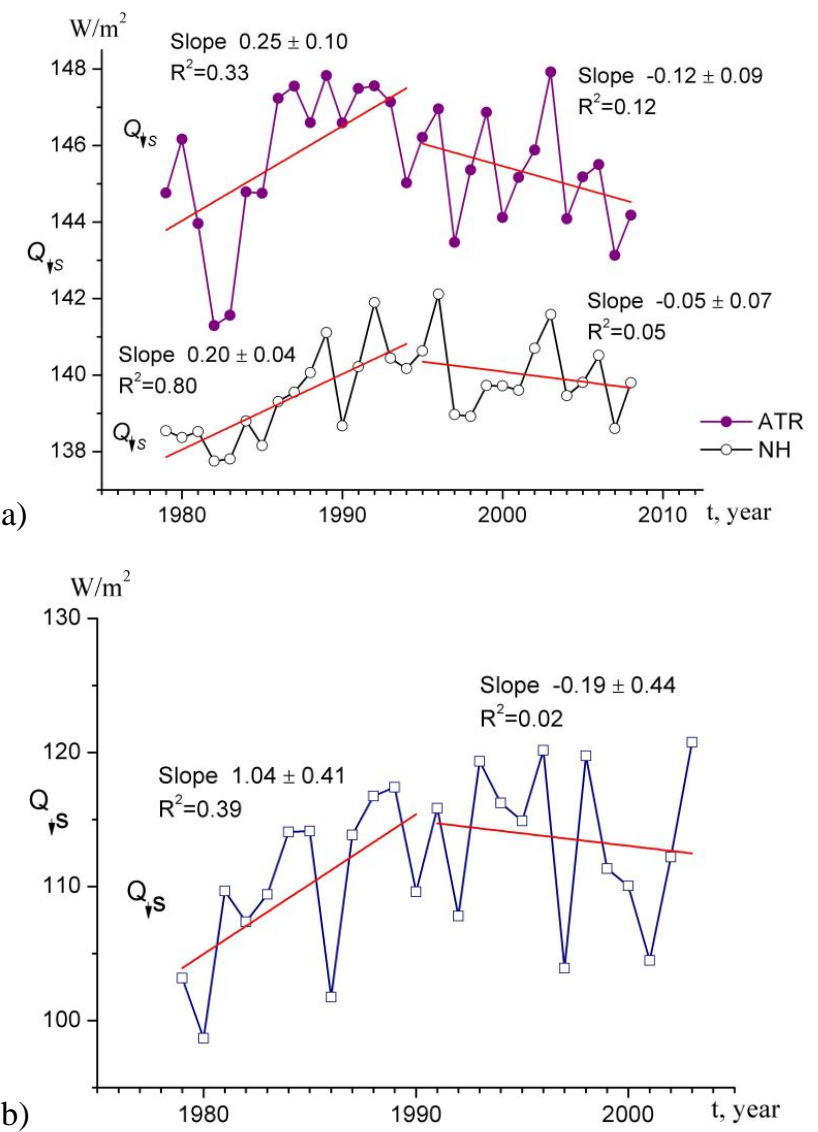

Fig. 3. The temporal variability of downward shortwave radiation at the surface $\mathrm{Q}_{\downarrow \mathrm{s}}$ by JRA-25 for the period of 1979-2008: zonally averaged values from $50^{\circ}$ to $60^{\circ} \mathrm{N}$ over ATR and Northern Hemisphere (a) and at Aleksandrovskoe station (60 26/ N. $77^{\circ} 52$ ' E) (b).

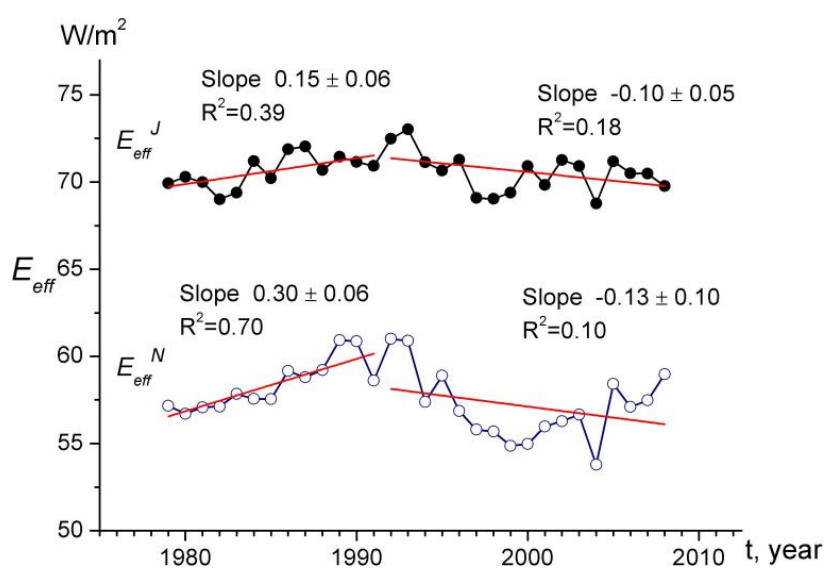

Fig. 4. The temporal variability of effective radiation $E_{\text {eff }}$ over ATR using JRA-25 reanalysis data for the period from 1979 to 2008.
(2011). These studies suggest that a reduction (increase) in latent heat increases (decreases) local surface temperatures due to the loss (gain) of evaporative cooling. It is confirmed by the analysis of JRA values, as well as observational data at stations (for example, in March at the Aleksandrovskoe $\left(60^{\circ} 26 / \mathrm{N}, 77^{\circ} 52 / \mathrm{E}\right)-0.07^{\circ} \mathrm{C} /$ decade, at Pudino $\left(57^{\circ} 32 / \mathrm{N}, 79^{\circ} 22 / \mathrm{E}\right)-0.28^{\circ} \mathrm{C} /$ decade, and at Barabinsk $\left(55^{\circ} 22 / \mathrm{N}, 78^{\circ} 24 / \mathrm{E}\right)-0.22^{\circ} \mathrm{C} /$ decade $)$. In summer the two times increasing of $\sigma$ is observed for $P$, as well as for its trends; it indicates that there are several areas with the processes occurring with different rates over ATR. Before summer the magnitudes of flux decreases over the territory of West Siberia and increases over the East Siberia. In summer the situation is opposite.

\section{Regression analysis of surface temperature variability versus heat balance components}

Air surface temperature variability mainly depends on heat and radiative balance elements variability, according to (1). Balance elements impacts was determined using regression model.

This regression model relates surface temperature anomalies $\delta T$ with relative shortwave radiation anomalies $\delta Q_{n}$, longwave radiation anomalies $\delta E_{\text {eff }}$, calculated for clear sky, anomalies of latent, sensibility heat, heat flux in the ground $\delta E g, E g=L E+P+G$, and with cloudiness anomalies $\delta \mathrm{TC}$ :

$\delta T=\beta_{1} \delta Q_{n}+\beta_{2} \delta E_{\text {eff }}+\beta_{3} \delta E g+\beta_{4} \delta \mathrm{TC}$,

Relationship between terms of the Eq. (3) for clear sky was determined by correlation coefficient and did not exceed 0.3 . This coefficient is statistically insignificant at $\alpha=0.05$ (it increased up to 0.5 only in March for shortwave radiation). However, as expected, when cloudiness is included in radiative fluxes correlation coefficient increases to 0.5 and to 0.9 for several months.

The influence of each level variability (high, medium and low cloud level) on temperature variability was also investigated (not presented). It was obtained that high level has the largest contribution to its varaibility in cold season, but medium and low cloud levels have an impact during warm season.

The addition of the total cloud to predictors allows to increase the contribution of describable regression $R^{2}$ (determination coefficient) in general by 0.06 , and for February and December - by 0.15 (Table 4), in that time the variability of $R^{2}$ was decreased in general by 0.02 . Such regression analysis (3) was carried out using NCEP/DOE AMIP-II reanalysis data, where we have found that determination coefficient is less by $15 \%$ than that according to JRA-25. We also investigated two subintervals, revealed in temporal variability of parameters under study. It was obtained that the contribution of describable regression $R^{2}$ for each separate subintervals (1979-1992 and 1992-2008) is higher than $R^{2}$ 
January

a)

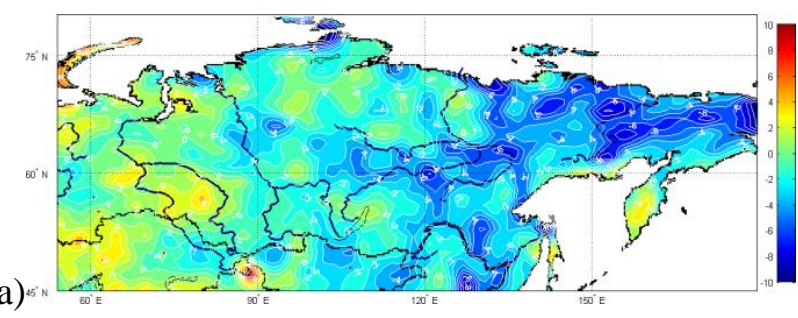

July

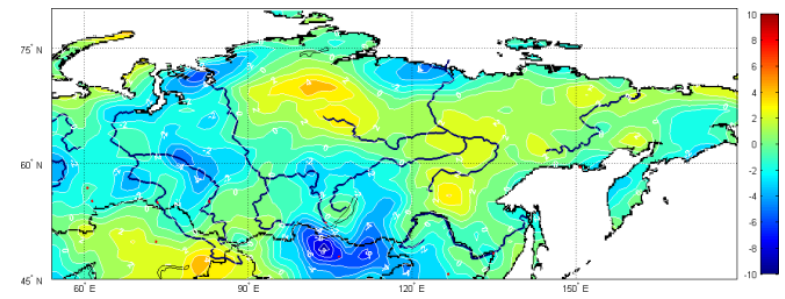

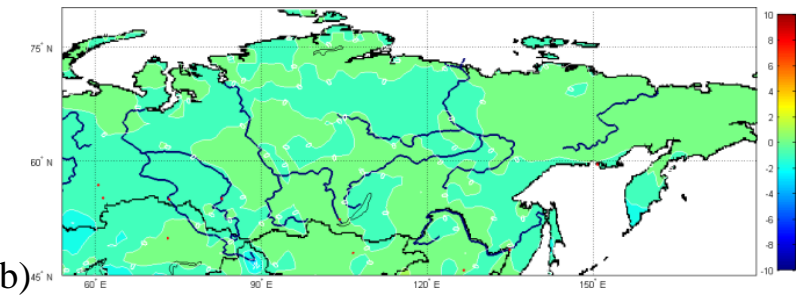
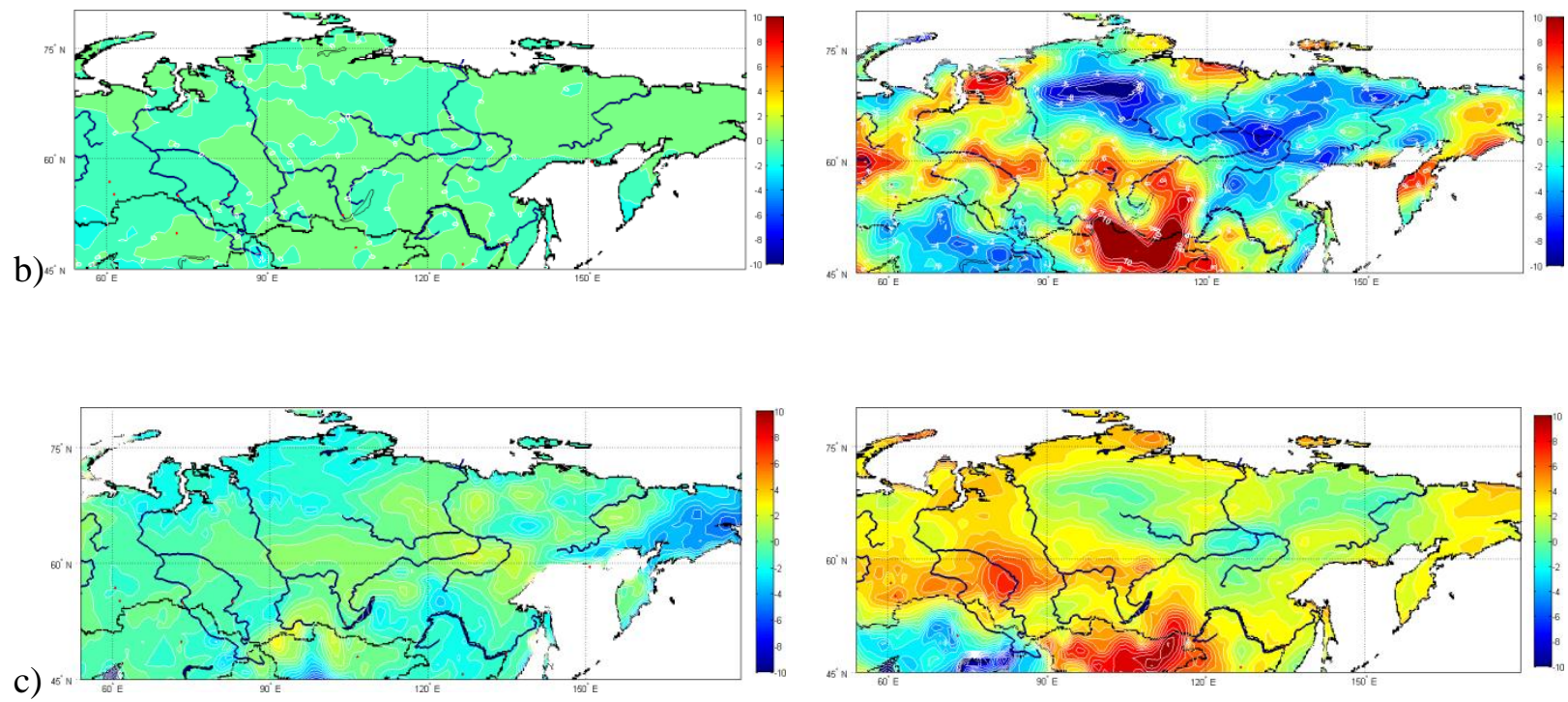

Fig. 5. The spatial variability of total cloud cover trend (TC, \%/decade) (a). Downward shortwave radiation trend at the surface $\left(Q_{\downarrow \downarrow}\right.$, $\mathrm{W} \mathrm{m}^{-2} /$ decade) (b) and effective radiation trend ( $E_{\text {eff }}, \mathrm{W} \mathrm{m}^{-2} /$ decade) (c) over ATR for January and July by JRA-25 for the period of 1979-2008.

for the whole period by 0.14 . The value of $R^{2}$ slightly varies within a year: for the first subinterval - from 0.76 to 0.9 ; for the second subinterval - from 0.69 to 0.87 .

It is seen from the Fig. 5, that the regions with high closeness of relationship $\left(R^{2}>0.8\right.$ on Cheddock scale, red color), and correspondingly with high level of prediction, are observed over coastal regions of Pacific ocean and over the northern part of West Siberia. In winter regions with very high relationship $\left(R^{2}>0.9\right.$ on Cheddock scale) are zonally extended and located in the central part of Western and Eastern Siberia. The coastal regions of Arctic ocean are characterized, as a rule, by a weak relationship $\left(R^{2}<0.3\right.$, blue color). In summer months the relation in the central part of ATR becomes weaker, but for coastal regions the increasing of the contribution of describable dispersion is observed. In spring and autumn there are local zones with high closeness of relationship mainly in the central and northern parts of ATR (Fig. 6).
In January, the largest contribution belongs to the effective radiation, i.e. to the balance of longwave radiation (Table 5). Table 5 shows that $\delta \mathrm{TC}$ and $\delta E g$ anomalies have the dominant influence $(>50 \%)$ on temperature variability $\delta T$ in November. In this month the areas of cloudiness influence are situated zonally over the mountain regions in southern part of ATR and in the northern part from Taimyr Peninsula to Chukotka Peninsula. In the region of Stanovoye Highlands $\delta$ TC anomaly describes up to $50-60 \%$ of temperature variability. The regions with increased influence of $\delta E g$ anomaly are situated along coastal areas and river systems.

\section{Conclusions}

Annual averaged temperature and radiative balance elements data, over Asian territory of Russia were analyzed for the years 1979-2008. Temperature trend over the territory is $0.48^{\circ} \mathrm{C} /$ decade according to reanalysis data. High positive 

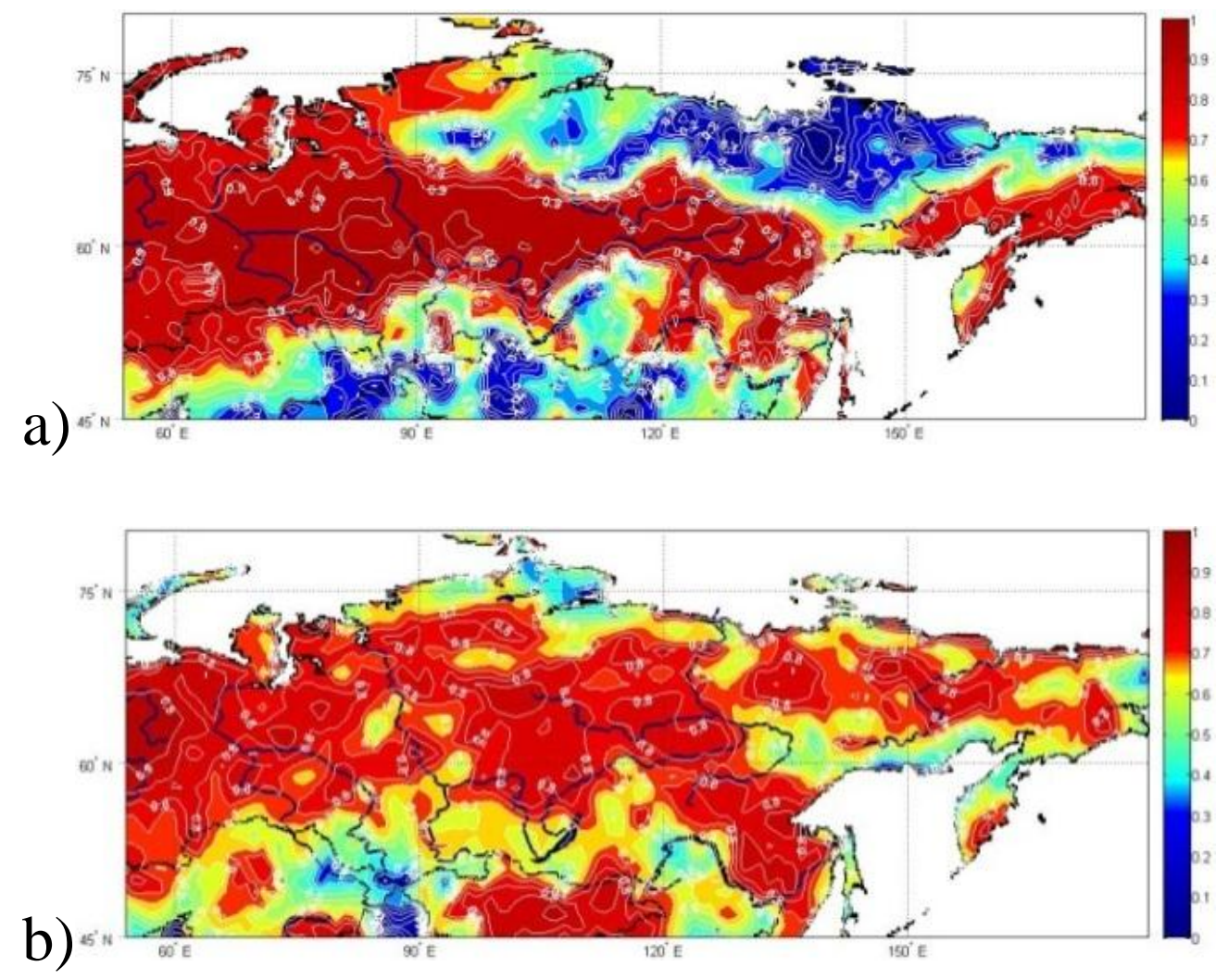

Fig. 6. The spatial distribution of determination coefficient $R^{2}$ calculated by (3) for January (a) and July (b) over ATR using JRA-25 reanalysis for the period of 1979-2008.

Table 4. Determination coefficient $\left(R^{2}\right)$ of regression model calculated by JRA-25 reanalysis for 1979-2008.

\begin{tabular}{lllll}
\hline \multirow{2}{*}{ Month } & \multicolumn{2}{c}{ Clear sky } & \multicolumn{2}{c}{ With cloudiness } \\
\cline { 2 - 5 }$R^{2}$ & $\sigma_{R^{2}}$ & $R^{2}$ & $\sigma_{R^{2}}$ \\
\hline Jan & 0.71 & 0.26 & 0.80 & 0.23 \\
Feb & 0.58 & 0.23 & 0.73 & 0.20 \\
Mar & 0.49 & 0.22 & 0.57 & 0.20 \\
Apr & 0.49 & 0.19 & 0.56 & 0.18 \\
May & 0.48 & 0.18 & 0.53 & 0.17 \\
Jun & 0.68 & 0.24 & 0.70 & 0.20 \\
Jul & 0.71 & 0.12 & 0.74 & 0.10 \\
Aug & 0.65 & 0.16 & 0.72 & 0.13 \\
Sep & 0.49 & 0.16 & 0.59 & 0.14 \\
Oct & 0.47 & 0.20 & 0.54 & 0.21 \\
Nov & 0.64 & 0.22 & 0.75 & 0.16 \\
Dec & 0.57 & 0.26 & 0.72 & 0.23 \\
\hline
\end{tabular}

Table 5. The contribution of each predictor in the regression model to the total variability of air surface temperature for the period 19792008. Statistically significant values are in bold.

\begin{tabular}{lllll}
\hline Month & $\delta \boldsymbol{Q n}$ & $\delta \boldsymbol{E}_{\text {eff }}$ & $\delta \boldsymbol{E} \boldsymbol{g}$ & $\delta \boldsymbol{T C}$ \\
\hline Jan & $\mathbf{2 6 . 8}$ & $\mathbf{3 7 . 2}$ & $\mathbf{2 0 . 2}$ & 15.8 \\
Feb & 20.0 & $\mathbf{4 1 . 3}$ & $\mathbf{2 1 . 5}$ & 17.3 \\
Mar & $\mathbf{2 1 . 5}$ & $\mathbf{4 2 . 1}$ & 15.3 & $\mathbf{2 1 . 1}$ \\
Apr & $\mathbf{5 0 . 6}$ & 14.9 & 6.4 & $\mathbf{2 8 . 1}$ \\
May & $\mathbf{5 3 . 8}$ & 17.9 & 6.5 & $\mathbf{2 1 . 8}$ \\
Jun & $\mathbf{4 3 . 8}$ & $\mathbf{3 2 . 0}$ & 10.8 & 13.4 \\
Jul & $\mathbf{4 5 . 3}$ & $\mathbf{2 3 . 3}$ & 15.5 & 15.9 \\
Aug & $\mathbf{3 9 . 7}$ & $\mathbf{3 0 . 4}$ & 19.0 & 10.9 \\
Sep & $\mathbf{3 5 . 0}$ & $\mathbf{3 6 . 4}$ & 14.1 & 14.5 \\
Oct & $\mathbf{2 0 . 2}$ & $\mathbf{3 1 . 6}$ & 17.2 & $\mathbf{3 1 . 1}$ \\
Nov & 7.3 & $\mathbf{3 5 . 9}$ & $\mathbf{2 4 . 4}$ & $\mathbf{3 2 . 4}$ \\
Dec & 19.5 & $\mathbf{3 6 . 8}$ & $\mathbf{2 5 . 7}$ & 18.0 \\
\hline
\end{tabular}


statistically significant temperature trends are revealed in March, May, June, July, August and October.

Regional variations of solar radiation flux obtained by reanalysis data are mainly conformed to total cloudiness and air temperature changes. In general, besides November, shortwave and longwave radiation play a major role in temperature variability (they describe $50 \%$ of this variability). From the beginning of 90s of 20th century the growth of solar radiation, reflected by earth's atmosphere is observed. This growth coincides with cloud cover dynamics and downward shortwave solar radiation coming to the surface.

We have presented a simple model for the description of temperature. Obtained regression model allow describing up to $70 \%$ of temperature variability using radiative factors.

Such research has shown that for several regions of ATR it is possible to predict air surface temperature variability using heat balance elements at the earth surface. For future investigation to get more accurate regression model, circulation processes in troposphere should be taken into account.

Acknowledgements. This work was supported by FPP 02.740.11.0738 and SB RAS VII.63.1.1. The authors also thank the editor and the anonymous reviewers for their helpful and constructive comments, which improved the manuscript considerably.

Edited by: M. Marconcini

\section{References}

Abakumova, G. M., Feigelson, E. M., Russak, V., and Stadnik, V. V.: Evaluation of long-term changes in radiation, cloudiness and surface temperature on the territory of the Former Soviet Union, J. Clim., 9, 6, 1319-1327, 1996.

Assesment report on climate change and its consequences in Russian Federation Climate Change, Federal Service for Hydrometeorology and Environmental Monitoring (ROSHYDROMET), 1, 227 pp., 2008.

Ban-Weiss, G. A., Bala, G., Cao, L., Pongratz, J., and Caldeira, K.: Climate forcing and response to idealized changes in surface latent and sensible heat, Environ. Res. Lett., 6, 034032, 8 pp., doi:10.1088/1748-9326/6/3/034032, 2011.

Boike, J., Wille, C., and Abnizova, A.: Climatology and summer energy and water balance of polygonal tundra in the Lena River Delta, Siberia, J. Geophys. Res., 113, G03025, doi:10.1029/2007JG000540, 2008.

Budyko, M. I.: The heat balance of the earth's surface / transl. from the Russ., edited by: Stepanova, N. A., Washington, US, Dept. of Commerce, Weather Bureau, 259 pp., 1958.

Chiacchio, M. and Wild, M.: Influence of NAO and clouds on longterm seasonal variations of surface solar radiation in Europe, J. Geophys. Res., 115, D00D22, doi:10.1029/2009JD012182, 2010.

Chernokulsky, A. V. and Mokhov, I. I.: Intercomparison of Global and Zonal Cloudiness Characteristics from Different Satellite and Ground Based Data, Issledovanie Zemli iz kosmosa, 3, 12 29, 2010.
Da Silva, A. M., Young, C. C., and Levitus, S.: Atlas of Surface Marine Data, Algorithms and Procedures, NOAA Atlas NESDIS 6, US Dept. of Commer., Natl. Oceanic and Atmos. Admin./ Natl. Environ. Satellite Data Inf. Serv., Silver Spring, Md., v.1, 1994.

Gupta, S. K., Ritchey, N. A., Wilber, A. C., Whitlock, C. H., Gibson, G. G., and Stackhouse, P. W.: A climatology of surface radiation budget derived from satellite data, J. Climate, 12, 2691$2710,1999$.

Ippolitov, I. I., Kabanov, M. V., Loginov, S. V., and Kharyutkina, E. V.: Structure and Dynamic of Meteorological Fields on the Asian Region of Russia in the Period of the Global Warming for 1975-2005, Journal of Siberian Federal University, Biology, 4, 1, 323-344, 2008.

Ippolitov, I., Gorbatenko, V., Loginov, S., Podnebesnych, N., and Kharyutkina, E.: The influence of atmospheric circulation on the climate over Western Siberia, Geophysical Research Abstracts, v.12, EGU2010-6600, 2010.

Iwahana, G., Machimura, T., Kobayashi, Y., Fedorov, A. N., Konstantinov, P. Y., and Fukuda, M.: Influence of forest clearcutting on the thermal and hydrological regime of the active layer near Yakutsk, eastern Siberia, J. Geophys. Res., 110, G02004, doi:10.1029/2005JG000039, 2005.

Khlebnikova, E. I. and Sall, I. A.: Peculiarities of climatic changes in cloud cover over the Russian Federation, Russ. Meteorol. Hydrol., 34, 7, 411-417, 2009.

Long, C. N., Dutton, E. G., Augustine, J. A., Wiscombe, W., Wild, M., McFarlane, S. A., and Flynn, C. J.: Significant decadal brightening of downwelling shortwave in the continental United States, J. Geophys. Res., 114, D00D06, doi:10.1029/2008JD011263, 2009.

Meroni, M., Mollicone, D., Belelli, L., Manca, G., Rosellini, S., Stivanello, S., Tirone, G., Zompanti, R., Tchebakova, N., Schulze, E. D., Valentini, R.: Carbon and water exchanges of regenerating forests in central Siberia, Forest Ecol. Manag., 169, 115-122, 2002.

Norris, J. R. and Wild, M.: Trends in aerosol radiative effects over China and Japan inferred from observed cloud cover, solar "dimming," and solar "brightening”, J. Geophys. Res., 114, D00D15, doi:10.1029/2008JD011378, 2009.

Pavlov, A. V.: Calculation and Regulation of the Cryotic Regime of Soil, Novosibirsk, Nauka, 240 pp., 1980.

Plakhina, I. N., Makhotkina, E. L., and Pankratova, N. V.: Variations of aerosol optical thickness of the atmosphere in Russia in 1976-2003, Russ. Meteorol. Hydrol., 32, 2, 85-92, doi:10.3103/S1068373907020021, 2007.

Plakhina, I. N., Pankratova, N. V., and Makhotkina, E. L. Variations in the atmospheric aerosol optical depth from the data obtained at the Russian actinometric network in 1976-2006, Izv. Atmos. Ocean. Phy., 45, 4, 456-466, doi:10.1134/S0001433809040069, 2009.

Riihimaki, L. D., Vignola, F. E., and Long, C. N.: Analyzing the contribution of aerosols to an observed increase in direct normal irradiance in Oregon, J. Geophys. Res., 114, D00D02, doi:10.1029/2008JD010970, 2009.

Rossow, W. and Zhang, Y.: Calculation of surface and top of atmosphere radiative fluxes from physical quantities based on ISCCP data set 2: Validation and first results, J. Geophys. Res., 100, 1167-1197, 1995.

Smith, G. L., Wilber, A. C., Gupta, S. K., and Stackhouse, P. W.: 
Surface radiation budget and climate classification, J. Climate, 15, 1175-1188, 2002.

Tchebakova, N. M., Kolle, O., Zolotoukhine, D., Arneth, A., Styles, J. M., Vygodskaya, N. N., Schluze, E.-D., Shibistova, O., and Lloyd, J.: Inter-annual and seasonal variations of energy and water vapour fluxes above a Pinus sylvestris forest in the Siberian middle taiga, Tellus, 54B, 537-551, 2002.

Trenberth, K. E. and Solomon, A.: The global heat balance: Heat transports in the atmosphere and ocean, Clim. Dyn., 10, 107134, 1994.

Trenberth, K. E. and Stepaniak, D. P.: The flow of energy through the Earth's climate system, Q. J. R. Meteorol. Soc., 130, 26772701, 2004.

Wilber, A. C., Smith, G. L., Gupta, S. K., and Stackhouse, P. W.: Annual cycles of surface shortwave radiative fluxes, J. Climate, 19, 535-547, 2006.
Zhang, Y.-C., Lacis, A. A., Oinas, V., and Mishchenko, M. I.: Calculation of radiative fluxes from the surface to top of atmosphere based on ISCCP and other global data sets: Refinements of the radiative transfer model and the input data, J. Geophys. Res., 109, D19105, doi:10.1029/2003J D00457, 2004.

Zhang, Y.-C. and Stackhouse Jr., P. W.: Comparison of different global information sources used in surface radiative flux calculation: Radiative properties of the near-surface atmosphere, J. Geophys. Res., 111, D13106, doi:10.1029/2005J D006873, 2006.

Zhang, Y.-C., Romanou, A., and Wielicki, B. A.: Decadal variations of global energy and ocean heat budget and meridional energy transports inferred from recent global data sets, J. Geophys. Res., 112, D22101, doi:10.1029/2007JD0068435, 2007. 